\title{
Keanekaragaman Hayati dan Konservasi Ikan Air Tawar
}

[Fish biodiversity and conservation in inland waters]

$$
\text { Lenny S Syafei }{ }^{\bowtie}
$$

Sekolah Tinggi Perikanan, Jurusan Penyuluhan Perikanan Jalan Cikaret Nomor 1Bogor 16001, Jawa Barat

Diterima: 02 Januari 2017; Disetujui: 27 Maret 2017

\begin{abstract}
Abstrak
Tujuan ulasan studi literatur keanekaragaman hayati dan konservasi ikan air tawar ini adalah untuk mendalami keanekaragaman hayati ikan di perairan tawar dan masalah eksistensi sebagian spesiesnya yang mulai terancam punah, serta faktor kesalahan pengelolaaan yang terjadi. Strategi global yang ditawarkan dalam ulasan studi literatur ini didasarkan atas pemilihan langkah konservasi sebagai jawaban untuk mengatasi ancaman kepunahan tersebut. Konservasi adalah perlindungan dan pelestarian kehidupan akuatik yang penting dalam menata keseimbangan alam dan mendukung ketersediaan sumberdaya bagi generasi yang akan datang. Tercatat spesies ikan yang ada di Indonesia berjumlah 1193 spesies dan keanekaragaman spesies ikan air tawar Indonesia nomor tiga terkaya di dunia. Ikan endemik adalah ikan yang keberadaannya hanya ada pada satu tempat tertentu, dan tidak ada di tempat lain. Ikan endemik di Indonesia berjumlah sekitar 120 spesies.Ditinjau dari sudut iktiogeografis, ikan air tawar di Indonesia mendiami tiga daerah sebaran geografis (Paparan Sunda, Daerah Wallace, dan Paparan Sahul) yang dibatasi oleh dua garis maya: Garis Wallace dan Garis Weber. Menetapkan tujuan dan sasaran konservasi; Merancang langkah-langkah pelaksanaan; Menyiapkan sarana dan prasarana pendukung yang diperlukan; Menentukan kriteria atau tolok ukur keberhasilan konservasi; dan Memantau serta mengevaluasi hasil berdasarkan kriteria yang telah ditetapkan.
\end{abstract}

Kata penting: keanekaragaman hayati ikan, konservasi ikan, perairan tawar

\begin{abstract}
The purpose of this review was to study about fish biodiversity and fish conservation in inland waters and to examine the potensial problem how a lot of species become extinct; off course also by mismanagement decision. The global strategy on this problem is based on chossing conservation as an answer to overcome that extinct species. Conservation it self was a principal of how to protection and preservation an important aquatic life as a part of arranging the balance of nature; and how to support the availability of resourses for future generations. The total amount of species fish in Indonesian was 1.193, beside that the biodiversity of Indonesia was record as the third richest-diversity in the world. Endemic fish is an fish whose their existence or their life cycle only in specific environment. The amount of endemic fish in Indonesia was record reach around 120 species. As a reviewed by ichthyogeografic sides, fresh water fish in Indonesia is spread and inhabit in three geografic area, that is: Paparan Sunda, Wallace area, and Paparan Sahul; which is limited of two imagine line: Wallace Line dan Weber Line. The Conservation purpose and its target, consists of: design implementation steps, prepare the necessary facilities and infrastructure, determine the criteria and benchmarks of succed conservation; and monitoring evaluation based on the criteria.
\end{abstract}

Keywords: fish biodiversity, fish conservation, inland waters

\footnotetext{
Penulis korespondensi

Alamat surel : Lenny Syafei
}

\section{PENDAHULUAN}

Masalah keanekaragaman hayati

telah menjadi wacana dalam masyarakat, terutama pada beberapa dasa warsa terakhir.Sejatinya apa yang dimaksud dengan keanekaragaman hayati itu dan 
mengapa perlu dikonservasi? Sebelum lebih jauh dibahas,baiklah dikemukakan terle-bihdahulu batasan (definisi) keanekaragaman hayati.

Keanekaragaman hayati adalah kekayaan hidup dibumi, tumbuhan, hewan, mikroorga -nisme, genetika yang dikandungnya, dan ekosistem yang dibangunnya menjadi lingkungan hidup. Dengan demikian keanekaragaman hayati adalah keseluruhan gen, spesiesdan ekosistem yang terdapat di dalam suatu wilayah.

Keanekaragaman spesies ikan menggambarkan seluruh cakupan adaptasi ekologi, serta menggambarkan evolusi spesies terhadap lingkungan tertentu. Maka dapat dipahami bila keanekaragaman ikan dapat berbeda dari satu lokasi ke lokasi lain. Persebaran ikan yang didasarkan atau dipandang dari sudut lokasi (letak geografis) disebut persebaran geografis atau sering diistilahkan sebagai iktiogeografi.

Kian besar jumlah spesies kian besar pula keanekaragaman hayati. Melalui proses evolusi yang terus menerus terbentuklah spesies baru (spesiasi). Sebaliknya, dengan terus menerus terjadi pula kepunahan spesies. Apabila laju terjadinya spesies baru lebih besar daripada laju kepunahan, maka jumlah spesies bertambah banyak. Keanekaragaman hayati pun kian naik. Bila hal sebaliknya yang terjadi, yaitu jumlah spesies berkurang manakala laju kepunahan lebih besar daripada laju terjadinya spesies baru, maka keanekaragaman hayati turun. Hal terakhir ini yang dikhawatirkan telah dan terus berlangsung dewasa ini, juga pada dunia ikan. Nguyen \& de Silva (1996) memperlihatkan jumlah spesies ikan yang terancam punah dibandingkan dengan total spesies di berbagai negara Asia (Gambar 1). Terlihat pada gambar tersebut di Indonesia jumlah spesies yang terancam punah mencapai sekitar $8 \%$.

Berangkat dari fakta di atas, ulasan ini membahas tentang keanekaragaman hayati ikan di perairan tawar dan masalah eksistensi sebagian spesiesnya yang mulai terancam punah, serta faktor

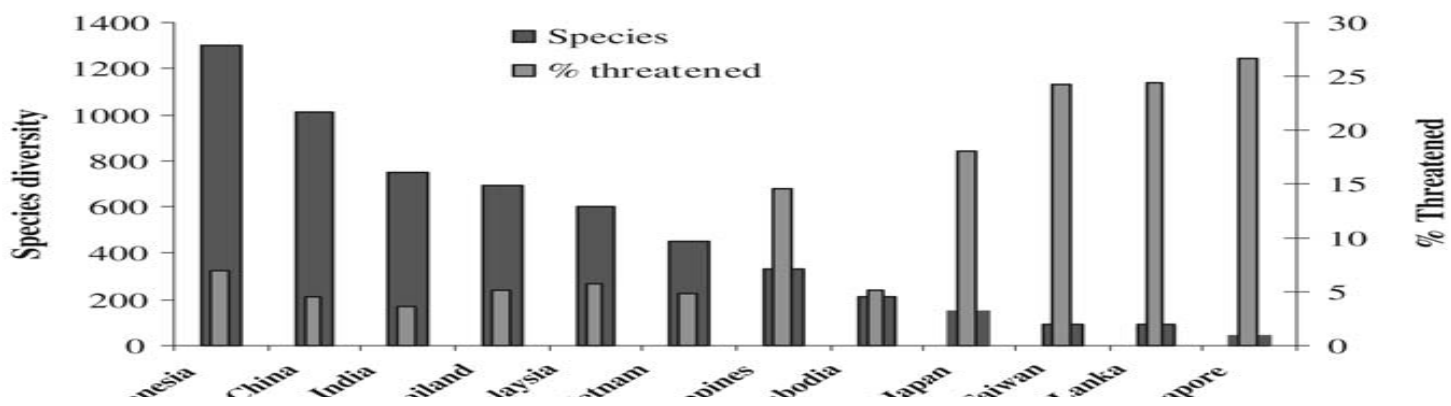

Gambar 1. Jumlah spesies ikan yang terancam punah di berbagai negara Asia yang dinyatakan dalam persen (Nguyen \& de Silva 1996) 


\begin{tabular}{lllll}
\hline No & Nama ilmiah & Nama inggris & Nama lokal & Lokasi \\
\hline 1 & Adrianichthys oophorus & Eggcarrying buntingi & Rono & Danau Poso \\
2 & Chilatherina sentaniensis & Sentani rainbowfish & & Danau Sentani \\
3 & Anguilla celebensis & Celebes longfin eel & sogili & Danau Poso \\
4 & Melanotaenia ajamaruensis & Ajamaru lakes rainbowfish & & Danau Ayamaru \\
5 & Melanotaenia arfakensis & Arfak rainbowfish & & Arfak \\
6 & Melanotaenia japenensis & Yapen rainbowfish & & Yapen \\
7 & Mugilogobius sarasinorum & Sarasin's goby & Bungu & Danau \\
8 & Oryzias matanensis & Matano medaka & & Danau Matano \\
9 & Telmatherina celebensis & Celebes rainbow & Opudi & Danau \\
\hline
\end{tabular}

Tabel 1. Beberapa spesies ikan endemik di Indonesia

yang menjadi akar permasalahan. Upaya

yang ditawarkan dalam ulasan ini adalahmelakukan konservasi sebagai jawaban untuk mengatasi ancaman kepunahan tersebut. Konservasi adalah perlindungan dan pelestarian kehidupan akuatik yang penting dalam menata keseimbangan alam dan mendukung ketersediaan sumberdaya bagi generasi yang akan datang.

\section{Keanekaragaman Hayati Ikan Air}

\section{Tawar}

Dari catatan yang dikumpulkan oleh Fishbase, spesies ikan yang ada di Indonesia berjumlah 1193 spesies (Froese \& Pauly 2013). Hal ini mendekati perkiraan Kottelat \& Whitten (1996) bahwa jumlah spesies ikan air tawar di Indonesia lebih kurang sebesar 1300 spesies. Keanekaragaman spesiesikan air tawar Indonesia nomor tiga terkaya di dunia di bawah0101(Froese \& Pauly 2013). Para ahli memperkirakan masih ada sekitar ratusan spesies ikan di wilayah Indonesia yang belum ditemukan dan dideskripsikan. Penemuan spesies baru dan revisi terhadap spesies yang ada terus berlangsung. Ini dapat dilihat antara lain dari tulisan Hadiaty \& Siebert (1998), Hadiaty \& Siebert (2001), Ng et al. (2004), dan Page et al. (2007).Penemuan spesies baru terus berlangsung. Salah satu yang monumental adalah ditemukannya spesies terkecil di dunia (Paedocypris progenetica) di perairan rawa-rawa Jambi. Ikan ini telahmencapai matang gonad pada panjang $0,76 \mathrm{~cm}$ (Kottelat et al. 2005).

Buku yang mendeskripsikan secara morfologis ikan Indonesia ditulis nyaris satu abad yang lalu ditulis oleh Max Weber \& de Beaufort (1911-1936) sebanyak tujuh jilid, yang kemudian dilanjutkan oleh de Beaufort dan rekannya (1940 - 1962) sebanyak empat volume. Buku yang berjudul "The fishes of the Indo-Australian Archipelago" 
tersebut mendeskripsikan ikan-ikan baik yang laut maupun air tawar dari morfologis luar. Sampai kini belum muncul satu buku pun yang memaparkan secara komprehensif seluruh kekayaan species ikan di Indonesia, khsususnya ikan perairan tawar. Meskipun secara nasional belum ada, namun ada beberapa buku tentang pemerian ikan pada satu kawasan tertentu di Indonesia; seperti Robert (1989) yang

menulis tentang ikan-ikan di Kalimantan Barat atau Kottelat et al. (1993) yang mengemukakan tentang ikan-ikan di Indonesia bagian Barat dan Sulawesi.Haryono \& Tjakrawidjaja (2004) menguraikan tentang ikan air tawar di Sulawesi Utara, sedangkan Rachmatika (2003) menjabarkan ikanikan yang menghuni Taman Nasional Gunung Halimun, Jawa Barat.
Sementara itu Simanjuntak et al. (2006) hanya membuat senarai ikan-ikan yang ditemukan di Sungai Kampar Kiri tanpa menguraikan secara rinci masing-masing spesies.

Berkaitan dengan keanekaragaman hayati ikan, perhatian perlu diarahkan kepada keberadaan ikan endemik danikan yang terancam punah di Indonesia.

\section{Ikan Endemik}

Ikan endemik adalah ikan yang keberadaannya hanya ada pada satu tempat tertentu, dan tidak ada di tempat lain. Ikan endemik di Indonesia berjumlah sekitar 120 spesies. Beberapa spesies ikan endemik diperlihatkan pada Tabel 1.

\section{Ikan Terancam Punah}

Beberapa ikan yang karena mengalami tekananpenangkapan yang

\begin{tabular}{clll}
\hline No & Nama ilmiah & Nama inggris & Nama lokal \\
\hline 1 & Balantiocheilos melanopterus & Tricolor sharkminnow & Batang buro \\
2 & Chilatherina bleheri & Bleher's rainbowfish & \\
3 & Chilatherina sentaniensis & Sentani rainbowfish & \\
4 & Telmatherina bonti & & Bonti-bonti \\
5 & Scleropages formosus & Asian bonytongue & Ikan siluk \\
6 & Osteochilus kappenii & & Kelajang \\
7 & Poropuntius tawarensis & & Keperas \\
8 & Oryzias marmoratus & Marmorated medaka & \\
9 & Rasbora subtilis & & Seluang \\
\hline
\end{tabular}

Tabel 2. Jenis-jenis ikan terancam punah 
intensif ataupunfaktor penyebab lain menjadi terancam punah. Keberadaan di perairan menjadi kian menipis. Beberapa di antara ikan tersebut dicantumkan dalam Tabel 2.

\section{Persebaran Geografis Ikan Air Tawar}

Ditinjau dari sudut iktiogeografis, ikan air tawar di Indonesia mendiami tiga daerah sebaran geografis (Paparan Sunda, Daerah Wallace, dan Paparan Sahul) yang dibatasi oleh dua garis maya: Garis Wallace dan Garis Weber (Gambar 2).Masing-masing daerah sebaran tersebut dihuni oleh berbagai spesies yang berbeda satu dari yang lain.

\section{Paparan Sunda}

Paparan Sunda mencakup pulau Sumatera, Jawa, Kalimantan, Bali, dan pulau-pulau kecil di sekitarnya. Pada masa lampau Paparan Sunda merupakan bagian dari benua Asia, yang kemudian terpisah pada zaman es sehingga terbentuk kondisi geografis seperti sekarang. Terdapat suatu teori yang menganggap bahwa ketika masa silam sungai-sungai yang mengalir ke timur pantai Sumatera, sungai yang mengalir ke selatan dari Vietnam,Muangthai, dan Birma, serta sungai yang mengalir ke arah barat Kalimantan merupakan anak sungai dari suatu sungai raksasa yang pernah mengalirdi antara Kalimantan dan India menuju ke Laut Cina Selatan.
Oleh karena itu ikan-ikan yang terdapat di pulau-pulau Sumatera, Jawa, dan Kalimantan sangat mirip dengan ikanikan di daratan Asia. Ikan yang tinggal di sungai-sungai Sumatera yang mengalir ke pantai timur dan ikan yang tinggal di sungai-sungai Kalimantan yang mengalir ke pantaibarat mempunyai banyak kesamaan. Sebaliknya, antara ikan-ikan penghuni Sungai Mahakam yang mengalir ke pantai timur dan ikan-ikan penghuni Sungai Kapuas yang mengalir ke pantai barat, terdapat perbedaan yang sangat besar; walaupun dua sungai tersebut terletak di pulau Kalimantan.

Sumatera dicirikan oleh perairan danau, sungai, dan rawa banjiran. Pada beberapa danau di Sumatera masih ditemukan ikan endemik, yang sebagian besar belum ada catatan aspek ekobiologisnya. Beberapa contoh ikan endemik misalnya: keperas (Poropuntius tawarensis) dan depik (Rasbora tawarensis) yang hidup di Danau Laut Tawar. Ihan atau dikenal sebagai ikan batak (Neolissochilus thienemanni) adalah ikan endemik di Danau Toba yang sekarang keberadaannya diragukan karena tidak pernah ditemukan lagi.

Tiga sungai besar mengalir di Kalimantan yaitu Kapuas, Barito dan Mahakam.Sekurangkurangnya dua spesies ikan endemik ditemukan di Sungai Kapuas yaitu 
kelajang (Osteochilus kappenii) dan seluang (Rasbora subtilis). Berbeda dengan pulau Sumatera dan Kalimantan yang keanekaragaman ikannya masih cukup besar, di Pulau Jawa ikan sudah banyak yang punah atau menipis populasinya.

\section{Daerah Wallacea}

Daerah Wallacea meliputi daerah Nusatenggara dan Sulawesi. Di daerah ini tidak begitu banyak terdapat spesies ikan air tawar.Ikan famili Cyprinidae dan Siluridae tidak menyebar di daerah ini. Ikan famili Cyprinidae yang ditemukan adalah hasil introduksi manusia, misal ikan tawes di Danau Tempe

Sebagian besar spesies penghuni daerah ini termasuk dalam kelompok ikan endemik. Beberapa contoh dapat dikemukakan antara lain Telmatherina antoniae, $T$. prognatha, dan $T$. opudi yang menghuni Danau Matano (Hadiaty \& Wirjoatmodjo, 2002). Kelompok ikan endemik selain ditemukan di danau ini, juga ditemukan di danau sekitarnya yang secara bersama-sama disebut Malili complex (Matano, Mahalona, Towuti, Masapi dan Wawantoa). Ikan-ikan yang ditemukan di sini mempunyai warna tubuh dan corak yang indah sehingga mempunyai potensi untuk dikembangkan sebagai ikan hias.

\section{Paparan Sahul}

Paparan Sahul yang bagian terluasnya adalah Papua, merupakan wilayah yang ikan-ikannya belum banyak diketahui karena kurangnya penelitian ke arah itu. Peneliti yang memberikan banyak kontribusi dalam mendeskripsikan ikan di Papua adalah Allen (1991, 1998, dan 2001) dan rekan (Allen et al. 2000). Di Paparan Sahul tidak ditemukan ikan-ikan dari Ordo Cypriniformes.

Beberapa jenis ikan yang hanya dapat dijumpai di sini ialah Glossolepis incisusdan Chilatherina sentaniensis yang menghuni di Danau Sentani. Di Danau Ayamaru ditemukan ikan-ikan Melanotaenia ajamaruensis, Melanotaenia boesmani, Glossogobius hoesei, dan Pseudomugil reticulatus. Sama halnya dengan ikan-ikan di Daerah Wallacea, ikan-ikan di sini mempunyai potensi dikembangkan sebagai ikan hias yang dapat menyejahterakan penduduk setempat.

\section{Ancaman terhadap keanekaragaman hayati ikan Beberapa faktor yang dapat} menjadi ancaman terhadap keanekaragaman hayati ikan dan menimbulkan kepunahan telah banyak dibahas oleh para pakar antara lain Gorena \& Ortal (1999), Nguyen \& de Silva (2006), dan Jurnal Penyuluhan Perikanan dan Kelautan 
Gosset et al. (2006). Secara umum dapat disarikan bahwa faktor ancaman tersebut ialah: tangkap lebih ikan, introduksi spesies baru, pencemaran, habitat yang hilang dan berubah, dan perubahan iklim global.

\section{Tangkap Lebih}

Dalam kaitannya dengan penangkapan ikan, sering terjadi orang melakukan penangkapan dengan alat yang membahayakan keberlanjutan populasi ikan. Alat tersebut adalah racun, bom dan setrum. Racun dan setrum efektif dalam menangkap ikan, namun yang terjadi bukan saja ikan sasaran yang tertangkap; juga ikan jenis lain dan anak-ikan yang bukan sasaran. Penggunaan bom sungguh sangat merusak.Pertama semua ikan dari segala ukuran mati dan ke dua habitat ikan hancur.

\section{Introduksi Spesies Baru}

Introduksi adalah suatu kegiatan manusia melepaskan atau memasukkan suatu spesies ikan baru yang sebelumnya tidak ada ke dalam suatu perairan. Menurut Welcomme (1988), introduksi telah dilakukan sejak lama, awal abad ke 19.Banyak alasan yang mendasari suatu spesies

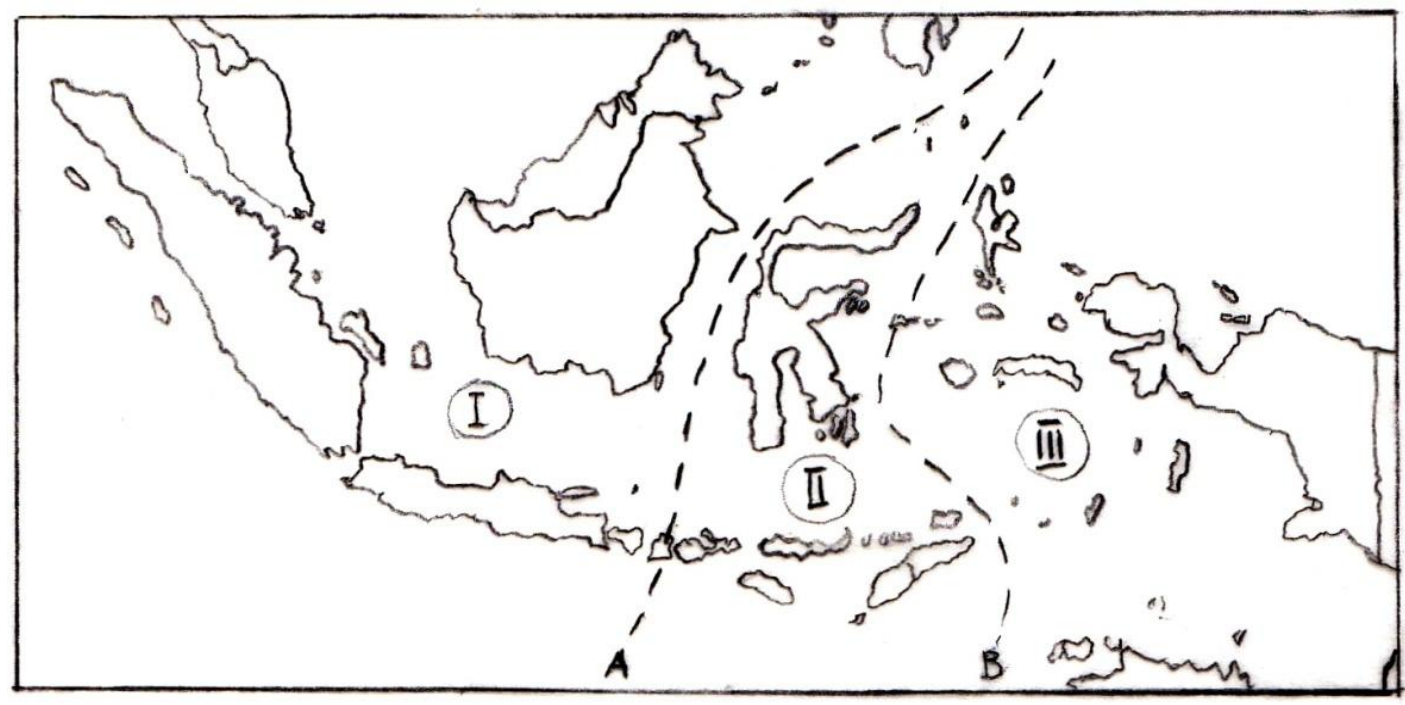

Gambar 2. Garis-garis batas iktiogeografi di kepulauan Indonesia. A. Garis Wallace, B. Garis Weber. I.Paparan Sunda, II.Daerah Wallacea, III. Paparan Sahul.

dimasukkan ke suatu perairan baru. perikanan untuk konsumsi atau Alasan tersebut antara lain: pemancingan, mengisi relung yang meningkatkan produksi perikanan di kosong, dan mengendalikan hama atau suatu perairan, mengembangkan jenis gulma (pengendalian biologis). Selain ikan yang lebih disenangi/disukai dalam 
alasantersebut, introduksi dapat terjadi karena ketidak sengajaan.

Banyak spesies ikan yang masuk ke perairan Indonesia, beberapa spesies masih diingat orang dan beberapa yang lain sudah dianggap ikan asli. Tabel 3 memperlihatkan spesies asing yang masuk ke Indonesia.
Ikan seribu (Poecilia reticulata) masuk ke Indonesia dengan tujuan untuk mengendalikan jentik-jentik nyamuk. Penebaran ikan bandeng (Chanos chanos) di Waduk Juanda, Jawa Barat dirancang untuk mengisi relung yang masih kosong, yaitu sumberdaya pakan

\begin{tabular}{clll}
\hline No & Nama Ilmiah & Nama Inggeris & Nama Indonesia \\
\hline 1. & Cyprinus carpio & Common carp & Mas \\
2. & Ctenopharyngodon idella & Grass carp & Koan \\
3. & Carassius auratus & Goldfish & Mas koki \\
4. & Oreochromis mossambicus & Mozambique tilapia & Mujair \\
5. & Oreochromis niloticus & Nile tilapia & Nila \\
6. & Clarias gariepinus & North African catfish & Lele dumbo \\
7. & Poecilia reticulata & Guppy & Seribu \\
8. & Trichogaster pectoralis & Snakeskin gourami & Sepat siam \\
9. & Parachromis managuensis & Jaguar guapote & \\
10 & Aequidens pulcher & Blue acara & \\
11 & Astronotus ocellatus & Oscar & \\
12 & Amphilophus citrinellus & Midas cichlid & \\
\hline
\end{tabular}

Tabel 3. Jenis species asing yang masuk ke perairan Indonesia

Orang mungkin sudah tidak ingat lagi bahwa ikan mas (Cyprinus carpio), ikan sepat siam (Trichogasterpectoralis), dan ikan mujair(Oreochromis mossambicus) bukan ikan asli Indonesia. Ikan-ikan tadi dikembangkan untuk meningkatkan produktivitas perairan.Ikan mas datang dari Cina dan sekarang tak dapat disangkal menjadi andalan dalam perikanan budidaya terutama di Jawa Barat. alami fitoplankton di Zona limnetik (bagian tengah) yang belum dimanfaatkan oleh ikan yang ada (Kartamihardja 2007). .

Ikan oskar (Amphilophus citrinellus) dan kongo (Parachromis managuensis) adalah ikan asing yang berkembang di Waduk Jatiluhur dan menjadi dominan. Diduga dua spesies ikan ini masuk ke waduk karena ketidaksengajaan, terbawa bersama benih ikan nila yang dipelihara di keramba jaring apung. Meskipun introduksi dapat memberikan hasil baik 
sesuai dengan tujuan introduksi, pada sisi lain masih mengemuka kekhawatiran bahwa. masuknya jenis ikan dapat mengganggu komunitas ikan asli yang ada. Beberapa kasus di Malaysia (Ali 1998) dan Spanyol (Elvira 1988) menguatkan kekhawatiran tersebut. Ikan introduksi dapat menyingkirkan ikan asli terjadi karena ikan asli kalah bersaing dengan ikan introduksi dalam mendapatkan pakan dan ruang pemijahan, atau ikan asli dimangsa oleh ikan introduksi. Pada situasi seperti ini spesies asing. tersebut tumbuh dan berkembang menjadi spesies invasif, dan dapat disebut pula sebagai "pencemar biologis".

Contoh yang spektakuler dan dramatis terjadi di Danau Victoria, Uganda. Ikan Lates niloticus yang diintroduksikan ke danau tersebut telah mengakibatkan lebih dari 200 spesies ikan endemik lenyap (Shoko 2005). Masih banyak contoh dari dampak sosial, ekonomi, dan lingkungan yang signifikan yang ditimbulkan oleh spesies asing invasif. Xie et al. (2001)mengulas balik spesies asing invasif di China. Sayang di Indonesia belum ditemukan tulisan yang secara menyeluruh mengulas tentang spesies asing invasif. Bahkan Peh (2010) menyatakan bahwa spesies asing invasif di Asia Tenggara belum banyak dipelajari.
Pencemaran (Permukiman, Industri, Pertanian)

Pencemaran adalah perubahan karakteristik lingkungan (fisik, kimiawi, biologis) ke arah kerusakan akibat masuknya bahan atau energi oleh kegiatan antropogenik. Pencemaran berpautan erat dengan reduksi keanekaragaman hayati ikan. Cemaran yang masuk ke perairan dapat berasal dari perindustrian (seperti logam berat, minyak, fenol, dan panas), pertanian (seperti herbisida, pestisida, dan pupuk), maupun permukiman penduduk. Cemaran dapat berakibat langsung pada kematian ikan, terutama larva dan yuwana ikan. Degradasi dan

\section{Fragmentasi Habitat}

Pembangunan sering mengubah bentang alam, termasuk perairan tawar sebagai habitat ikan. Pembendungan sungai untuk menjadi waduk menjadikan sungai terfragmentasi. Kondisi ini menghalangi ikan yang melakukan ruaya pemijahan ke arah hulu atau sebaliknya ke hilir, sehingga dapat memutus keberlanjutan populasi ikan tersebut. Selain itu, perubahan dari habitat mengalir menjadi habitat tergenang menciutkan keanekaragamanhayati ikan riverin, dan sebaliknya menguntungkan bagi ikan lacustrin. Keanekaragaman hayati ikan di waduk menurun dibandingkan keanekaragaman 
hayatiikan di sungai utama di Cina ( $\mathrm{Li}$, 2001).Dampakbendungan terhadap keanekaragaman hayati ikan dan biota lainnya dipaparkan secara komprehensif oleh McAllister et al. (2001). Meningkatnya kekeruhan, pendangkalan, dan debit yang sungai yang sangat fluktuatif antara musim penghujan dan kemarau menambah panjang daftar keterancaman keanekaragaman hayati ikan di sungai akibat degradasi habitat. Beberapa contoh perairan yang telah mengalami pendangkalan yang berat yaitu Bengawan Solo di Jawa Tengah. Eutrofikasi di danau menyebabkan kondisi tidak nyaman bagi ikan akibat adanya deplesi oksigen. Belum lagi adanya alih fungsi perairan menjadi peruntukan lain seperti permukiman, kawasan industri, dan perdagangan tanpa memperhatikan lingkungan merupakan lonceng kematian bagi keanekaragaman hayati ikan.

\section{Perubahan Iklim}

Menarik untuk menyinggung masalah keanekaragaman hayati dengan perubahan iklim. Perubahan iklim telah mengakibatkan suhu air naik di sungai, danau, dan perairan tawar lainnya. Naiknya suhu perairan ini akan langsung memengaruhi ikan yang termasuk golongan poikilotermik.Kenaikan suhu akan mempertinggi tingkat metabolisme.
Diperlukan energi lebih banyak untuk mempertahankan diri, sehingga energi lebih banyak untuk perawatan dibandingkan untuk pertumbuhan. Ikan mengalokasikan energi dari makanannya ke belanja energi. Hal ini mengakibatkan pertumbuhan ikan melambat, atau ikan tersebut harus mencari makan dengan lebih banyak agar pertumbuhan kembali normal. Hal ini masih perlu penelitian lebih lanjut.

Kenaikan suhu juga memengaruhi kehidupan organisme yang menjadi mangsa ikan. Melalui rantai makanan, perubahan ini akansecara berurutan memengaruhi ikan padajenjangtrofik yang lebih tinggi. Dengan demikian secara keseluruhan dapat saja terjadi perubahan biomassa masing-masing jenis organisme pada setiap jenjang trofik, sehingga komposisi organisme di perairan termasuk ikan dapat berubah.

Perubahan ini dapat dimaknai sebagai bertambahnya tekanan bagi kehidupan ikan. Bukan tidak mungkin beberapa ikan tertentu dapat punah karena tidak mampu beradaptasi. Secara umum, tidaklah mudah memprakirakan respons ikan per spesies terhadap perubahan iklim, karena ketiadaan atau tidak lengkapnya informasi ekologi dan biologinya.

Suhu akan menurunkan kelarutan oksigen dalam air. Oksigen terlarut 
adalah suatu parameter penentu dan pembatas ikan, yang memengaruhi sintasan, pertumbuhan, pemijahan, kinerja berenang, perkembangan larva, dan tingkah laku ruaya. Jumlah oksigen yang dibutuhkan oleh ikan sangat bervariasi dan bergantung kepada spesies, ukuran, jumlah makanan yang diambil, aktivitas, suhu air, konsentrasi oksigen terlarut, dan lain-lain. Berkurangnya oksigen terlarut akan mengarah pada kondisi hipoksia (kekurangan oksigen), bahkan dapat menjadi anoksia (ketiadaan oksigen). Kondisi ini akan sangat menekan ikan, dan dapat mematikan.

Mengacu pada keterangan di atas, jelaslah bahwa perubahan iklim memengaruhi keanekaragaman hayati. Konsekuensi perubahan iklim pada komponen spesies dari keanekaragaman hayati mencakup: perubahan laju pertumbuhan, perubahan dalam ruaya dan distribusi, perubahan dalam waktu reproduksi, dan perubahan dalam rekrutmen dan mortalitas. Peluang hilangnya suatu spesies ikan meningkat seiring dengan perubahan iklim.

\section{Konservasi ikan}

Ancaman akan kepunahan spesies ikan ini masih belum sepenuhnya disadari dan dipahami oleh banyak kalangan. Seringkali terjadi mereka baru tersadar ketika segalanya sudah terlambat karena kekayaan plasma nutfah hilang. Pertanyaan yang mengemuka adalah apa tindakan yang perlu dilakukan agar kepunahan spesies atau penurunan keanekaragaman hayati ikan dapat dicegah.Jawabannyaadalah perlu tindakan konservasi ikan. Konservasi tidak boleh dimaknai hanya sekedar spesies tidak punah, melainkan lebih dari itu. Pada hakekatnya konservasi ikan adalah upaya perlindungan, pelestarian, dan pemanfaatan ikan. Dalam praksisnya, konservasiikan dapat dilakukan melalui dua cara yaitu konservasi in situdan konservasi ex situ.

\section{Konservasi in Situ}

Konservasi in situ adalah perlindungan populasi dan komunitas di habitat alaminya. Perlindungan spesies bukan sekedar melindungi spesies itu sendiri, tetapi juga lingkungannya. Ini adalah bentuk konservasi yang terbaik mengingat satu populasi tidak dapat hidup sendiri. Dia memerlukan interaksi dengan spesies lain dan lingkungannya.

Langkah-langkah yang ditempuh untuk melaksanakan konservasi in situ ialah: (a) pembatasan eksploitasi (alat, waktu, dan area); (b) pencegahan 
kerusakan lingkungan perairan; dan (c)penetapan daerah lindungan (reservat).

\section{Konservasi ex Situ}

Konservasi ex situ adalah perlindungan populasi di luar habitat alaminya. Konservasi ex situ tidaklah mudah. Banyak spesies yang bila dibawa keluar dari habitat aslinya tidak mudah beradaptasi dengan lingkungan barunya. Upaya yang perlu dilakukan ialah: (a) membuat suatu kolam atau lingkungan perairan yang meniru lingkungan habitat asli spesies; (b)menyediakan pakan alami.

Kedua cara konservasi tersebut (ex situ dan in situ) saling melengkapi. Bila pada konservasi ex situ spesies dapat tumbuh dan berkembang, maka sebagian individu dari populasi tersebut secara berkala dilepaskan ke habitat aslinya.

\section{Peta Jalan Konservasi}

Pelaksanaan konservasi baik ex situ maupun in situmemerlukan data dasar sebagai pertimbangan agar dapat mencapai hasil sesuai dengan tujuan yang ditetapkan.Data dasar yang diperlukan dalam konservasispesies mencakup antara lain: (a) ciri morfologis, (b) Distribusi dan struktur populasi, (c) Reproduksi dan pertumbuhan, (d) Perilaku, (e) Interaksi biotik (pemangsaan dan persaingan), dan

(f) Lingkungan (hayati dan nir hayati).

Bagaimana cara mengumpulkan informasi atau data tersebut di atas? Pertama, pengumpulan data dan informasi dapat diperoleh melalui studi pustaka(buku, jurnal ilmiah, makalah teknik, laporan). Kedua,data dikumpulkan dari hasil penelitian di lapangan maupun di laboratorium.

Langkah selanjutnya adalah kumpulan data dasar dipilah, dikelompokkan, dan dianalisis sehingga memberikan pemahaman menyeluruh lengkap dan rinci tentang ikan sasaran.

Pemahaman ini dijadikan landasan dan acuan dalam menetapkan peta jalan konservasi sumber daya ikan, yang melingkupi: (a) Menetapkan tujuan dan sasaran konservasi; (b) Merancang langkah-langkah pelaksanaan; Menyiapkan sarana dan prasarana pendukung yang diperlukan; Menentukan kriteria atau tolok ukur keberhasilan konservasi; serta (e) Memantau dan mengevaluasi hasil berdasarkan kriteria yang telah ditetapkan

\section{Penutup}

Masalah keanekaragaman hayati ikan belum banyak dipahami oleh sebagian masyarakat, terlebih lagi perihal konservasi. Pengetahuan tentang 
ikan masih sedikit yang telah diungkap dan dipelajari. Berangkat dari titik ini, jelas masih dibutuhkan lebih banyak eksplorasi untuk lebih memahami, agar bukan hanya keanekaragamanikan terjaga, tetapi juga dapat dimanfaatkan bagi kesejahteraan masyarkat. Begitu banyaknya spesies yang ada di Indonesia, sayangnya dalam kenyataan masih sedikit spesies yang dimanfaatkan.

Sungguh luar biasa bila nanti ikanikan endemik di suatu daerah dapat dimanfaatkan apakah sebagai ikan konsumsi atau sebagai ikan hias andalan daerah tersebut. Ketika kita mampu melestarikan spesies ikan dari kepunahan, maka itu adalah cerminan penghormatan kita kepada alam. Alam yang telah memberikan banyak kebaikan bagi hidup dan kehidupan kita.

\section{Daftar Pustaka}

Ali AB. 1998. Impact of fish introductions on indigenous fish population and fisheries in Malaysia. In: I.G. Cowx (editor): Stocking and introduction of fish. Fishing News Books, London, pp. $274-286$.

Allen GR. 1991. Field guide to the freshwater fishes of New Guinea. Christensen Research Institute, Madang - Papua New Guinea. $268 \mathrm{p}$.

Allen GR. 1998. A new genus and species of Rainbowfish (Melanotaeniidae) from fresh waters of Irian Jaya, Indonesia.
Revue Française d'Aquariologie 25 (1-2): 11-16

Allen GR. 2001. A New Species of Rainbowfish (Glossolepis: Melanotaeniidae) from Irian Jaya, Indonesia. Fishes of Sahul, 15(3): 766-775

Allen GR, Hortle KG, Renyaan SJ. 2000. Freshwater fishes of the Timika region New Guinea. PT Freeport Indonesian Company, Timika. $175 \mathrm{p}$.

David Dudgeon, Angela H. Arthington, Mark O. Gessner, Zen-Khiro Kawabata, Duncan J. Knowler, Christian Leveque, Robert J. Naiman, Anne-Helene PrieurRichard, Doris Soto, Melanie L.J. Stiassny, Caroline A. Sulivan, 2006. Freshwater biodiversity: Importance, threats, status and conservation challenges. Biological Reviews, volume 81, issue 2, May 2006, Pages 163$182 . \quad$ e-mail: ddudgeon@hkucc.hku.hk

de Beaufort LF. 1940-1962. The fishes of the Indo-Australian Archipelago, vol. 8 - 11. E. J. Brill, Leiden.

Elvira B. 1998. Impact of introduced fish on the native freshwater fish fauna of Spain. In: Cowx IG (editor): Stocking and introduction of fish. Fishing News Books, London, pp. $186-$ 190.

Froese R \& Pauly D. Editors. 2013. Fish Base. Worl Wide Web electronic publication. www.fishbase.org. version $(04 / 2013)$

Gorena M \&Ortal R. 1999. Biogeography, diversity and conservation of the inland water fish communities in Israel. Biological Conservation 89: 1 9

Jurnal Penyuluhan Perikanan dan Kelautan 
Gosset C, J. Rives, J. Labonne. 2006. Effect of habitat fragmentation on spawning migration of brown trout (Salmo trutta L.). Ecol. Freshw. Fish 2006: 15: 247-254

Hadiaty RK \& Siebert DJ, 1998. Two new species of Osteochilus (Teleostei: Cyprinidae) from Sungai Lembang, Suag Balimbing Research Station, Gunung Leuser National Park, Aceh, Northwestern Sumatra. Revue Francaise d'Aquariologie Herpetologie Journal., 25 (1-2): 1-4

Hadiaty RK \& Siebert DJ. 2001. Nemacheilus tuberigum, a new species of loach (Teleostei: Balitoridae) from Aceh, northwestern Sumatra, Indonesia. Bull. Nat. Hist. Mus. Lond. (Zool.), 67 (2): 183-189

Hadiaty RK \& Wirjoatmodjo S. 2002. Studi pendahuluan biodiversitas dan distribusi ikan di Danau Matano, Sulawesi Selatan. Jurnal Iktiologi Indonesia 2 (2): 23 - 29

Haryono \& Tjakrawidjaja AH. 2004. The freshwater fishes of North Sulawesi. Bidang Zoologi Puslit Biologi LIPI, Bogor. 120 p.

Kartamihardja ES. 2007. Spektra ukuran biomassa plankton dan potensi pemanfaatannya bagi komunitas ikan di zona limnetik Waduk Ir. H. Djuanda, Jawa Barat. Disertasi. Sekolah Pascasarjana, IPB. $137 \mathrm{p}$.

Kottelat M, Whitten AJ, Kartikasari SN, Wirjoatmodjo S. 1993. Ikan air tawar Indonesia bagian barat dan Sulawesi. Periplus, Hongkong. 293 p +84 plates.
Kottelat M \& Whitten T. 1996. Freshwater biodiversity in Asia with special reference to fish. World Bank Technical Paper $343,59 \mathrm{p}$.

Kottelat M, Britz R, Hui TH, Witte KE. 2005. Paedocypris, a new genus of Southeast Asian cyprinid fish with a remarkable sexual dimorphism, comprises the world's smallest vertebrate. Proceedings of the Royal Society: Biological Sciences: 1 - 5

Li S 2001. The impact of large reservoirs on fish biodiversity and fisheries in China. In: De Silva S.S. (ed.), Reservoir and Culture-Based Fisheries: Biology and Management. ACIAR Conference Proceedings 98, Canberra, Australia, pp. 22-28.

McAllister DE, Craig JF, Davidson N, Delany S, Seddon M. 2001. Biodiversity Impacts of Large Dams. IUCN, UNEP or UNF. 68 p.

$\mathrm{Ng} \mathrm{HH}$, Wirjoatmodjo S, Hadiaty RK. 2004. Kryptopterus piperatus, a new species of silurid catfish (Teleostei: Siluri-formes) from northern Sumatra. Ichthyol. Explor. Freshw. 15(1): 91-95

Nguyen TTT \& de Silva SS. 2006. Freshwater finfish biodiversity and conservation: an asian perspective. Biodiversity and Conservation 15:3543-3568

Page LM, Hadiaty RK, Lopez JA, Rachmatika I, Robins RH. 2007. Two new species of the Akysis variegatus species group (Siluriformes: Akysidae) from Southern Sumatra and a redescription of Akysis variegatus Bleeker, 1846. Copeia (2): 292-303 
Peh KSH. 2010. Invasive species in Southeast Asia: the knowledge so far. Biodiversity Conservation, 19: 1083-1099

Rachmatika I. 2003. Fish fauna of the Gunung Halimun National Park, West Java. Biodiversity Conservation Project.126 p.

Roberts TR. 1989. The freshwater fishes of western Borneo (Kalimantan Barat, Indonesia). California Academy of Sciences. $210 \mathrm{p}$

Shoko APA, Ngowo RR, Waya RK. 2005. Deleterious effects of nonnative species introduced into Lake Victoria, East Africa. Naga, 28 (3 \& 4): $27-32$

Simanjuntak $\mathrm{CPH}$; Rahardjo $\mathrm{MF}$, Sukimin S. 2006. Iktiofauna di rawa banjiran Sungai Kampar Kiri. Jurnal Iktiologi Indonesia, 6 (2): $75-78$

Weber M \& de Beaufort LF. 1911-1936. The fishes of the Indo-Australian Archipelago, vol. 1 - 7. E. J. Brill, Leiden.
Welcomme, R.L. 1988. International introductions of inland aquatic species. FAO Fisheries Technical Paper, (294): 318 p.

Xie Y, Li Z, Gregg WP, Li D. 2001. Invasive species in China - an overview. Biodiversity and Conservation, 10: 1317-1341

David Dudgeon, Angela H. Arthington, Mark O. Gessner, Zen-Khiro Kawabata, Duncan J. Knowler, Christian Leveque, Robert J. Naiman, Anne-Helene PrieurRichard, Doris Soto, Melanie L.J. Stiassny, Caroline A. Sulivan, 2006. Freshwater biodiversity: Importance, threats, status and conservation challenges. Biological Reviews, volume 81, issue 2, May 2006, Pages 163$182 . \quad$ e-mail: ddudgeon@hkucc.hku.hk 